\title{
Outcome of premature thelarche: relation to puberty and final height
}

\author{
S Salardi, E Cacciari, B Mainetti, L Mazzanti, P Pirazzoli
}

\begin{abstract}
Background-There is a debate about the possible progression of idiopathic premature thelarche towards precocious or early puberty.

Objective-To evaluate height and age at onset of puberty in a group of girls with a history of idiopathic premature thelarche. Study design-The height and age at onset of puberty of 42 girls now over 10 years of age who were diagnosed with isolated premature thelarche before the age of 3 years were evaluated.

Results-Menarche was reached before or at 11 years of age in $13.5 \%$ of this group of girls. This percentage of early menarche was higher than would be expected from historical controls in the general population, but was consistent with maternal age of menarche. The mean (SD) height of the girls $(n=15)$ who achieved adult height was $162.9(6.3) \mathrm{cm}$, which was slightly higher than the mean (SD) relative midparental height $(160.7(6.7) \mathrm{cm})$.

Conclusions-Isolated premature thelarche with onset before 3 years of age progresses towards precocious puberty, although this was consistent with the maternal age of menarche. Furthermore, adult height was normal when compared with population norms in all patients. (Arch Dis Child 1998;79:173-174)
\end{abstract}

Keywords: premature thelarche; early menarche; adult height; midparental height; puberty

Premature thelarche has been defined as an isolated non-progressive development of the breast, with no other signs of sexual maturation or acceleration in growth rate and bone maturation, in girls under 7 or 8 years of age, which is prevalent in 2-3 year old girls. ${ }^{1}$ Some authors think that the condition is self limiting, with no repercussions on the future timing of puberty, ${ }^{23}$ while others ${ }^{4}$ have described a possible risk of precocious or early puberty. In part, these discrepancies might be because some cases, especially those patients over 3 years of age, should be categorised as slowly progressing forms of central precocious puberty, ${ }^{5}$ or so-called "thelarche variant" ${ }^{\prime 6}$ and not as that of typical premature thelarche.

Because of these discordant opinions, we decided to evaluate the pubertal and auxological outcome of our patients with premature thelarche, many of whom had already been studied some 10 years before with pelvic ultrasonography and hormonal tests. ${ }^{7}$ In total, we reassessed 23 of the 40 girls included in our earlier study in addition to 19 other girls with the same characteristics, whom we had examined successively. All patients were more than 10 years old.

\section{Patients}

We examined 42 patients who had previously been diagnosed with isolated premature thelarche. Their age at the last examination ranged from 10 to 20.5 years (median, 13.0). The median interval between diagnosis and last examination was 11 years, with a range of 7.16-18.08 years. The characteristics of the patients are reported in table 1 . These girls had all the characteristics of typical premature thelarche: the average age of onset was less than 1 year, with $94 \%$ being within the first 18 months of life (in $50 \%$ of cases, thelarche was present from birth); mean (SD) age at diagnosis was $1.80(0.85)$ years and mean (SD) bone age was 2.10 (1.15) years. In reality, five cases presented advanced bone age and, thus, according to the definition of typical premature thelarche, should not have been included in this group. However, we included them because both at diagnosis and during follow up they showed no other characteristics that differentiated them from the other children. Because these cases could be included in the category of "exaggerated thelarche", ${ }^{8}$ they were also evaluated as a separate subgroup.

Twenty seven girls (six of them postmenarcheal) are still growing (group A), and 15 girls (all of them postmenarcheal) have already reached adult height (group B).

\section{Methods}

The height of the girls was measured using a Harpenden stadiometer. Corrected midparental height was calculated with the formula: mother height + father height $-13 / 2$. Bone age was determined according to Greulich and Pyle's atlas': we considered bone age scores $>2 \mathrm{SD}$ above the mean as advanced, according to the same atlas. We established that adult height was attained if statural growth was $<0.5 \mathrm{~cm}$ in the last year. A 3.5 or $5 \mathrm{MHz}$ real time sector scanner (models SRT and RT 3000; General Electric Medical Systems Group, Milwaukee, Wisconsin, USA) was used for pelvic ultrasonography performed at diagnosis.

\section{STATISTICAL ANALYSIS}

Significance was assessed using the two tailed Student's $t$ test and correlation analysis. All $\mathrm{p}$ values $<0.05$ were considered significant. All values are expressed as mean (SD).

\section{Results}

The height of the girls $(n=15)$ who had achieved adult height (group B) ranged between 
Table 1 Clinical characteristics of the girls with premature thelarche occurring before 3 years of age

\begin{tabular}{|c|c|c|c|c|c|c|c|c|c|}
\hline & \multirow{2}{*}{$\begin{array}{l}\text { Age at onset } \\
\text { (years) }\end{array}$} & \multirow{2}{*}{$\begin{array}{l}\text { Current } \\
\text { age (years) }\end{array}$} & \multirow{2}{*}{$\begin{array}{l}\text { Breast } \\
\text { regression }\end{array}$} & \multirow{2}{*}{$\begin{array}{l}\text { Current } \\
\text { height } \\
\text { (centile) }\end{array}$} & \multirow{2}{*}{$\begin{array}{l}\text { Adult } \\
\text { height } \\
\text { (cm) }\end{array}$} & \multicolumn{2}{|c|}{ Midparental height } & \multirow{2}{*}{$\begin{array}{l}\text { Menarcheal } \\
\text { age (years) }\end{array}$} & \multirow{2}{*}{$\begin{array}{l}\text { Maternal menarcheal } \\
\text { age (years) }\end{array}$} \\
\hline & & & & & & Centile & $\mathrm{cm}$ & & \\
\hline All subjects $(n=42)$ & $0.65(0.82)$ & $12.81(2.37)$ & $76 \%$ & & & & & $12.2(1)(\mathrm{n}=21)$ & $12.6(1.43)(\mathrm{n}=21)$ \\
\hline Group A $(\mathrm{n}=27)$ & $0.64(0.97)$ & $11.38(1.17)$ & $84 \%$ & $70.2(21.8)$ & - & $41.6(27.3)$ & - & $11.6(1.2)(\mathrm{n}=6)$ & $12.0(1.4)(\mathrm{n}=6)$ \\
\hline Group B $(\mathrm{n}=15)$ & $0.66(0.60)$ & $15.38(1.72)$ & $71 \%$ & - & $162.9(6.3)$ & - & $160.7(6.7)$ & $12.4(0.9)(\mathrm{n}=15)$ & $12.9(1.42)(\mathrm{n}=14)$ \\
\hline
\end{tabular}

Group A, girls who are still growing; Group B, girls who have achieved adult height.

Table 2 Characteristics of the girls with menarcheal age $\leqslant 11$ years ${ }^{\star}$ or advanced bone agef at diagnosis

\begin{tabular}{|c|c|c|c|c|c|c|c|c|c|c|}
\hline \multirow[b]{2}{*}{ Case } & \multirow{2}{*}{$\begin{array}{l}\text { Bone age at } \\
\text { diagnosis (SDS) }\end{array}$} & \multirow{2}{*}{$\begin{array}{l}\text { Breast } \\
\text { regression }\end{array}$} & \multirow{2}{*}{$\begin{array}{l}\text { Current } \\
\text { age (years) }\end{array}$} & \multicolumn{2}{|c|}{ Current height } & \multirow{2}{*}{$\begin{array}{l}\text { Adult } \\
\text { height (cm) }\end{array}$} & \multicolumn{2}{|c|}{ Midparental height } & \multirow{2}{*}{$\begin{array}{l}\text { Menarcheal } \\
\text { age (years) }\end{array}$} & \multirow{2}{*}{$\begin{array}{l}\text { Maternal } \\
\text { menarchea } \\
\text { age (years) }\end{array}$} \\
\hline & & & & $\mathrm{cm}$ & Centile & & $\mathrm{cm}$ & Centile & & \\
\hline \multicolumn{11}{|c|}{ Group $A$} \\
\hline $1^{\star}$ & -0.6 & Yes & 11.75 & 147.2 & 50 & - & 154.5 & 10 & 11.00 & 12 \\
\hline $2^{\star}$ & - & Yes & 11.50 & 161.5 & $>97$ & - & 154.5 & 10 & 10.33 & 11 \\
\hline $3^{\star}$ & +1.1 & - & 11.00 & 160.6 & 97 & - & 171.5 & 95 & 10.50 & 11 \\
\hline $4 \dagger$ & +2.2 & Yes & 11.75 & 152.8 & 75 & - & 167.5 & 80 & $>$ Current age & 12 \\
\hline $5+$ & +7.9 & Yes & 13.42 & 173.4 & $>97$ & - & 168.5 & 85 & 13.00 & 10 \\
\hline $6 t$ & +2.8 & Yes & 12.75 & 157.8 & 70 & - & 161.0 & 40 & $>$ Current age & 12 \\
\hline $7 \dagger$ & +4.2 & Yes & 11.25 & 152.2 & 85 & - & 162.0 & 50 & $>$ Current age & 12 \\
\hline \multicolumn{11}{|c|}{ Group B } \\
\hline $8^{\star}$ & +1.7 & Yes & 14.16 & - & - & 160.2 & 156.5 & - & 10.92 & 12 \\
\hline $9^{\star}$ & 0 & Yes & 16.75 & - & - & 166.0 & 159.5 & - & 10.82 & 12 \\
\hline $10 \dagger$ & +3.4 & No & 16.08 & - & - & 167.3 & 161.5 & - & 13.82 & 13.5 \\
\hline
\end{tabular}

Group A, girls who are still growing; Group B, girls who have achieved adult height.

†Advanced bone age defined as $>2$ standard deviation scores (SDS).

150.1 and $173.4 \mathrm{~cm}$, with a mean value slightly more than their midparental height (table 1). The mean (SE) difference between adult and midparental heights was $1.85(1.44) \mathrm{cm}$. Only one child presented an adult height at the third percentile $(150.1 \mathrm{~cm})$, with a midparental height of $154 \mathrm{~cm}$ : this was a girl with abnormal responses to four growth hormone stimulation tests, untreated because of the simultaneous presence of type I diabetes mellitus.

The menarcheal age of the 21 menstruating girls (six from group A and all 15 of group B; table 1) correlated with that of their mothers $(r=0.44 ; \mathrm{p}=0.05)$. Twenty eight per cent of the mothers and $13.5 \%$ of the daughters (five of the 37 girls who had reached 11 years) had had an early menarche - that is, at $\leqslant 11$ years. The five girls with early menarche and the five girls with advanced bone age at diagnosis (table 2) showed a centile of their current height, or an adult height, equal to or greater than their relative midparental height.

\section{Discussion}

We were unable to date the onset of puberty in many cases because intermediate clinical observations were missing. Therefore, we used the age of menarche as a marker for the precocity of pubertal development. In line with Tanner, ${ }^{10}$ who reported that the menarcheal age in $95 \%$ of the girls in his study was between 11 and 15 years, we considered the onset of menarche before 11 years as precocious. Even taking into consideration the limitations arising from the comparison with data from a different population and the absence of an endogenous control group in our study, the percentage of early menarche $(13 \%)$ appears to be higher than expected for the general population. In the present series, bone age advancement could not identify those subjects at risk of early or precocious puberty.

However, rather than being the consequence of past thelarche, this early timing of puberty seemed to be the result of a genetic predisposition, because early menarche was consistent with early maternal age of menarche. Moreover, in disagreement with previous reports, ${ }^{4}$ the height of the girls with early menarche was normal compared with the general population (that is, $>5$ th centile) and in all patients height was normal for midparental height.

In conclusion, our data suggest that some patients with premature thelarche progress into precocious or early puberty, although this seems to be a reflection of early maternal menarche. However, this does not affect the prognosis for a normal adult height, even in the small subgroup with advanced bone age. Therefore, if height prognosis is the only reason for switching off early puberty, we can affirm that there is no need for treatment in these cases. However, there could be good social/emotional reasons for wishing/needing to switch off early puberty, irrespective of height prognosis.

1 Wilkins L. The diagnosis and treatment of endocrine disorders in childhood and adolescence. 3rd ed. Springfield: Charles C Thomas, 1965:206.

2 Van Winter JT, Noller KL, Zimmerman D, Melton LJ III. Natural history of premature thelarche in Olmsted County, Minnesota, 1940 to 1984. F Pediatr 1990;116:278-80.

3 Garibaldi L. Progression of premature thelarche to precocious puberty. F Pediatr 1995;127:336.

4 Pasquino AM, Pucarelli I, Passeri F, Segni M, Mancini MA, Municchi G. Progression of premature thelarche to central precocious puberty. $\mathcal{F}$ Pediatr 1995;126:11-14

5 Fontoura M, Brauner R, Prevot C, Rappaport R. Precocious puberty in girls; early diagnosis of a slowly progressing variant. Arch Dis Child 1989;64:1170-6.

6 Stanhope R, Brook CGD. Thelarche variant: a new syndrome of precocious sexual maturation? Acta Endocrinol 1990;123:481-6.

7 Salardi S, Orsini LF, Cacciari E, et al. Pelvic ultrasonography in girls with precocious puberty, congenital adrenal hyperplasia, obesity, or hirsutism. F Pediatr 1988;112:8807 .

8 Garibaldi LR, Aceto T Jr, Weber C. The pattern of gonadotropin and estradiol secretion in exaggerated thelarche. Acta Endocrinol 1993;128:345-50.

9 Greulich WW, Pyle SI. Radiographic atlas of skeletal development of the hand and wrist. 2nd ed. Palo Alto: Stanford University Press, 1959.

10 Tanner JM. Foetus into man. 2nd ed. Castlemead Publications, 1989. 